GESTÃO DE OPERAÇÕES E LOGÍSTICA 


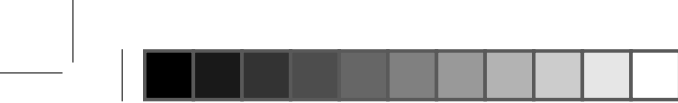

GESTÃO DE OPERAÇÕES E LOGÍSTICA

\title{
ALTERAÇÕES NOS HÁBITOS DE COMPRA E DISTRIBUIÇÃO VAREJISTA
}

\author{
CHANGES IN SHOPPING HABITS AND DISTRIBUTION IN RETAIL
}

Kenyth Alves de Freitas

Fundação Getúlio Vargas

Ricardo Silveira Martins

Universidade federal de Minas Gerais

\author{
Data de submissão: 04 jul. 20 |7. Data de aprovação: \\ 20 jan. 2018 . Sistema de avaliação: Double blind review. \\ Universidade FUMEC / FACE. Prof. Dr. Henrique Cordeiro \\ Martins. Prof. Dr. Cid Gonçalves Filho.
}

RESUMO

O crescimento das aglomerações urbanas tem causado restrições à mobilidade de pessoas e cargas, levando os consumidores a reduzirem a propensão a deslocamentos para compras. Sendo assim, o objetivo deste estudo é a busca de evidência de quais ramos de atividade do varejo podem ser apontados como mais sensíveis a volta do consumidor ao comércio local, bem como discutir os impactos da redistribuição espacial desta parte do varejo para a logística de distribuição nas cidades. Para isso, foram utilizados dados secundários das escolhas de locais de compra da base de dados da Pesquisa dos Orçamentos Familiares (POF) do Instituto Brasileiro de Geografia e Estatística (IBGE), através de uma pesquisa básica, descritiva e quantitativa. Foram evidenciadas mudanças dos hábitos de compra mais contundentes para alimentos e produtos de higiene pessoal, cosméticos e perfumaria. Quanto mais se compra nos bairros, mais entregas são necessárias, portanto, mais veículos de carga circulando, menos mobilidade das pessoas, e, por conseguinte, menor propensão a deslocarem-se.

\section{PALAVRAS-CHAVE}

Mobilidade Urbana.Varejo. Locais de Compra. Distribuição. POF. 


\section{ABSTRACT}

The growth of urban areas has caused restrictions on mobility of both people and goods, leading consumers to reduce the willingness to displacements for shopping and thereby generating a spatial reorganization of city and business. Thus, the central question that this study sought to address is a search for evidence which retail lines of business can be pointed as more sensitive to this shopping behavior for convenience and discuss the impacts of spatial redistribution of this part of retail for logistics distribution in cities. For this, we used secondary data of shopping local choices of the search database of Family Budgets (POF) of the Brazilian Institute of Geography and Statistics (IBGE), through a basic, descriptive and quantitative research. Changes of the most compelling shopping habits for food and personal care products, toiletries, cosmetics and perfumes were found as results. The more you purchase in neighborhoods, more supplies are needed, thus more load vehicles circulating, less mobility, and therefore less likely to move up.

\section{KEYWORDS}

Urban Mobility. Retail. Stores. Urban Logistics. Distribution. POF.

\section{INTRODUÇÃO}

O Brasil passou por intenso processo de urbanização no último século, resultando no salto da taxa de urbanização de $31 \%$, em 1940, para, aproximadamente, 85, $1 \%$ em 2014 (INSTITUTO BRASILEIRO DE GEOGRAFIA - IBGE, 20I4). A concentração populacional nas grandes cidades criou alguns problemas para a população que ali reside, tais como o comprometimento da mobilidade e a diminuição da qualidade de vida geral. Além destes de caráter pessoal, outras questões no campo da logística também foram impactadas, como a dificuldade na movimentação urbana de cargas, com o consequente problema de suprimento dos estabelecimentos comerciais implicando impactos nos custos e no "nível de serviço" nos relacionamentos com o varejo (LIMA JÚNIOR, 20II).
Além das dificuldades originadas na maior aglomeração urbana e as dificuldades que são impostas para a movimentação de cargas e suprimentos do varejo, a logística também tem lidado com outros elementos complicadores originados nas forças de mercado. Conforme destaca Zinn (20 I2), a multiplicidade de produtos e serviços desejados por clientes e de pontos de entrega são ingredientes de ainda maior complexidade neste ambiente desfavorável. Este contexto parece gerar uma contradição: os consumidores desejam ser atendidos com uma variedade cada vez maior de produtos disponíveis em diversas formas de acesso, mas têm sua qualidade de vida prejudicada em função da redução de mobilidade e da poluição atribuídas à frota de cargas (LIMA, 2003, ZINN, 20I2).

Desta forma, os consumidores tendem a 
reduzir a propensão a deslocamentos para compras, em especial, as mais rotineiras. Conforme sustenta Lima Júnior (20II), a redução da mobilidade os induz a buscarem alternativas mais convenientes, por proximidade para realizarem as compras. Corrêa (1989), reforça este contexto assinalando que as ações dos agentes urbanos levam ao processo de reorganização espacial da cidade, incorporando novas áreas e ou alterando o caráter de outras, por exemplo, criando ou reforçando comércio local. Estudo realizado pelo instituto de pesquisa Euromonitor (20I5), confirma a tendência da volta do consumidor ao pequeno comércio do bairro, indicando a preferência do consumidor em realizar suas compras gastando o menor tempo possível nesta atividade.

A questão central que este estudo se propõe a responder é: Se e como as complexidades da mobilidade urbana têm influenciado as decisões de locais de compra e alterado o equilíbrio de forças no varejo?

Dessa forma, o objetivo que norteou essa pesquisa foi a busca por evidências de quais ramos do varejo podem ser apontados como mais sensíveis ao comportamento de compra por conveniência, avaliando o papel das deficiências de mobilidade urbana, a redistribuição espacial desta parte do varejo e seu impacto na logística de distribuição das grandes cidades. Para a realização desse objetivo foram utilizados os dados coletados na Pesquisa dos Orçamentos Familiares (POF), realizada pelo IBGE, nas edições 1995/1996, 2002/2003 e 2008/2009.

O setor varejista, além de sua clara importância econômica e social, tem sofrido alterações em função das mudanças de comportamento dos consumidores. De acordo com Grandini (2009), o consumidor valoriza mais o tempo e a conveniência na compra do que a marca e, em alguns casos, que o preço do produto (PARENTE, 2000; LIMA JÚNIOR, 20II). Apesar disso, existe uma carência de estudos sobre logística urbana de cargas no Brasil (OLIVEIRA, 20I3; GATTI JÚNIOR, 20I I), em especial, de trabalhos que tratem da relação entre logística e mobilidade urbana (GATTI JÚNIOR, 20I I).

\section{MARCOTEÓRICO}

As competências logísticas têm a função de criar as condições para que a compra se concretize nos termos estabelecidos entre empresas e clientes. Bens e serviços têm pouco ou nenhum valor de mercado se não estiverem disponíveis para consumo no lugar e no tempo necessários (MENTZER; STANK; ESPER, 2008; ARSHINDER; KANDA; DESHMUKH, 20I I).

Nesse contexto, inserem-se os desafios relacionados à mobilidade de cargas e pessoas nos grandes centros urbanos. Problemas de mobilidade urbana impactam as operações de distribuição de mercadorias e as estratégias de multiplicidade de locais de compra e, por fim, influenciam o comportamento do consumidor (LIMA, 2003; ZINN, 20I2).

Para Lima Júnior (20II), a falta de planejamento das cidades brasileiras é a causa essencial dos problemas de mobilidade e logística urbanas.As cidades não foram planejadas para abrigar uma sociedade da informação nem para comportar o crescimento da população ou a demanda por serviços urbanos decorrente desse aumento populacional.

Os desafios de mobilidade urbana impactam a movimentação de cargas nas cidades, resultando em dificuldades para a manutenção dos serviços logísticos e para a viabilidade operacional. Além disso, os problemas de mobilidade urbana interferem na qualidade de vida e no comporta- 
mento do consumidor, que buscam alternativas mais viáveis para manter o próprio consumo (LIMA JÚNIOR, 20 I I).

O varejo tem como características importantes o dinamismo e a rapidez em se adaptar às necessidades do consumidor. $A$ disponibilidade do produto é uma questão chave para o varejista, visto que tempo e lugar são decisivos para a concretização da compra (ARSHINDER; KANDA; DESHMUKH, 20II). Ao mesmo tempo, manter os suprimentos em níveis baixos de estoque se tornou desafiador a partir das crescentes deficiências advindas da urbanização (LINDHOLM; BEHRENDS, 20I2).

Estudo realizado pelo Euromonitor (20I5), intitulado Global Consumer Trends For 2015, identificou a tendência da valorização da conveniência por parte do consumidor. $O$ qual resulta no crescimento das compras pela internet e na volta dos consumidores ao pequeno comércio de bairro. Embora o comércio eletrônico esteja se tornando mais importante a cada ano, as vendas realizadas por lojas físicas ainda são dominantes, em especial na América Latina.

De acordo com Silva e Cleps (20II), existe forte tendência no setor, em especial no varejo de alimentos, de se decompor em dois tipos de formatos de loja: a grande loja, para compras mensais e ou planejadas, e as lojas de bairro, para compras frequentes e ou emergenciais. As lojas de bairro são caracterizadas pela reduzida área de vendas, proximidade com a residência do consumidor e oferta restrita de itens e marcas. $O$ principal critério para a escolha deste tipo de estabelecimento pelo consumidor é a conveniência, mesmo que esse atributo signifique um valor um pouco maior na compra do mesmo produto.

Os bairros periféricos, inicialmente des- tinados apenas a abrigar os domicílios das famílias, começaram a acolher filiais das lojas centrais e pequenos comércios, com o objetivo de suprir as necessidades cotidianas da população do entorno. Com o crescimento populacional e o aumento da renda, este tipo de varejo se tornou mais dinâmico originando os centros de comércio de bairro, os chamados "subcentros comerciais" (PINTAUDI, I98I; BALLANTYNE; LINDHOLM;WHITEING, 20I3).

A infraestrutura de transporte e a eficiência do sistema implicam diretamente o tempo de viagem, o custo e o esforço com que os moradores das cidades têm de lidar diariamente. Essas restrições criam oportunidades para que empreendimentos próximos, com o atributo de conveniência, se multipliquem em localidades que facilitem o acesso do consumidor e alterem o uso da terra destinado a certa localidade. Essas novas centralidades passam a acolher filiais das lojas centrais e pequenos comércios com o objetivo de suprir as necessidades cotidianas da população do entorno, afetadas pelos problemas de acessibilidade (PINTAUDI, I98I; FUJITA, 1988).

Para os consumidores, a preferência por lojas mais próximas do domicílio atende ao atributo temporal e a busca por conveniência. Segundo pesquisa realizada pelo Euromonitor (20/5), a conveniência é apontada como uma das principais tendências para varejo, em especial em cidades em grandes cidades, em que o fator tempo é mais valorizado. $O$ surgimento de novas centralidades ao longo da cidade e crescimento do comércio de bairro em número e diversidade são resultados diretos dessa nova realidade.

\section{MÉTODOS DA PESQUISA}

Esta pesquisa pode ser considerada como uma pesquisa básica, ou seja, que não

12 R. Adm. FACES Journal Belo Horizonte v. 17 n. 3 p. 8-27 jul./set. 2018. ISSN 1984-6975 (online). ISSN 1517-8900 (Impressa) http://dx.doi.org/10.21714/1984-6975FACES2018V17N3ART5278 
objetiva uma aplicação prática imediata, mas visa gerar novos conhecimentos para o avanço do campo de estudo científico. Além disso, pode ser classificada como uma pesquisa descritiva quantitativa que busca nas características de certa população descrever um fenômeno através da análise de informações quantificáveis (GIL, 20I5).

$O$ estudo foi desenvolvido nas regiões metropolitanas brasileiras, por meio da investigação dos dados da Pesquisa de Orçamentos Familiares (POF). A base de dados da POF contempla uma série de informações dos produtos adquiridos pelos moradores do domicílio, incluindo os locais de compra utilizados na aquisição. Entre os mais de 600 locais de compra observados na pesquisa, estão: supermercados, vendedores ambulantes, padarias, lanchonetes, açougues, peixarias, feiras livres, drogarias, entre outros (IBGE, 20I4).

Com base nas alterações nos locais de compra de determinados produtos ao longo das últimas três edições da POF, no período compreendido entre 1995 e 2008, este trabalho pretende identificar fatores como multiplicidade de pontos de venda, transferência de locais de compra e crescimento de consumo em locais de compra comumente próximos ao domicílio das famílias, tratando essas alterações como uma resposta logística aos desafios da mobilidade urbana nos grandes centros.

\section{Característica e fonte dos dados}

Para responder à pergunta central deste trabalho, foram selecionadas algumas das variáveis observadas na POF:

- CÓDIGO DA UF DA DESPESA identifica a Unidade da Federação onde foi efetuada a aquisição do produto ou serviço.
- ESTRATO GEOGRÁFICO - identifica os estratos do plano amostral da pesquisa: estratificações geográficas e estatísticas. No nível geográfico, a estratificação compreende: área urbana para o município da capital, resto da região metropolitana, resto da UF e área rural.

- NÚMERO DO QUADRO - identifica os agrupamentos de produtos específicos do questionário de despesas. Na última edição da pesquisa (2008/2009), foram levantados I3.77| itens de consumo das famílias.

- FORMA DE AQUISIÇÃO - identifica se a forma de aquisição do item foi por meios monetários (compra e aluguel) ou por meios não monetários (doações e produção própria).

- LOCAL DE COMPRA - identifica o tipo de local onde o produto ou serviço foi adquirido. Dentre os mais de 600 locais de compra observados na última edição da pesquisa, estão supermercado, vendedor ambulante, padaria, lanchonete, açougue, peixaria, feira livre, drogaria, entre outros (IBGE, 20I4).

Como a POF observa o consumo de mais de 10 mil itens, foi considerada mais apropriada a análise por grupos de produtos. A variável número do quadro agrupa os itens de consumo do mesmo tipo, para facilitar a análise dos dados. Dentre os agrupamentos da POF, cinco grupos de despesas foram selecionados para análise, envolvendo produtos perecíveis, bens de consumo não duráveis e bens duráveis. Entre os bens não duráveis estão os todos os produtos alimentícios identificados pela POF (produtos perecíveis); artigos de higiene, inclui artigos de higiene pessoal (escovas de dente e apa- 
relho de barbear), cosméticos (cremes e loções) e artigos de perfumaria (colônias e perfumes); e artigos de vestuário: inclui artigos de vestuário masculinos, femininos e infantis. Os bens de consumo duráveis estão representados pelos artigos eletrônicos, que incluem aparelhos elétricos, como eletrodomésticos, eletroeletrônicos e equipamentos para o uso no lar.

\section{Análise dos dados}

Os dados dessa pesquisa foram analisados com o objetivo de identificar a transferência dos locais de compra do varejo nas aquisições de bens das famílias brasileiras, considerando que a partir disso será possível estabelecer um paralelo entre a escoIha do local de compra e os problemas de mobilidade que afligem as metrópoles brasileiras. A análise descritiva foi considerada adequada para responder à questão central da pesquisa, proporcionando informações sumarizadas dos dados contidos no total de elementos da amostra (MATTAR, 200 I).

$A$ análise descritiva utilizada nesta pesquisa foi a distribuição de frequência da variável locais de compra, utilizando as variáveis número do quadro e estrato geográfico para delimitar os grupos de análise. A distribuição de frequência visa obter uma contagem do número de respostas associadas a diferentes categorias de uma variável em forma de percentagem e a tabulação cruzada é uma técnica que descreve duas ou mais variáveis de modo simultâneo, originando tabelas que refletem a distribuição conjunta dessas variáveis com um número limitado de categorias (MALHOTRA, 200I).

\section{APRESENTAÇÃO E ANÁLISE DOS RESULTADOS}

O varejo é um setor altamente adaptá- vel às necessidades dos consumidores e o comércio de produtos alimentícios não é diferente, tendo sofrido profundas mudanças nos últimos anos, em especial com o surgimento de novos formatos, ajustados a atender às novas necessidades dos consumidores. A criação desses empreendimentos, no entanto, não significa a extinção dos formatos anteriores (ROGERS et al., 2005; BURT; MAVROMMATIS, 2006).

A partir dos dados do grupo de Despesa com Produtos Alimentícios, é possível saber qual formato varejista foi escolhido no momento da compra pelas famílias pesquisadas. A Figura I apresenta os locais de compra mais frequentes na aquisição de alimentos e sua participação relativa ao longo de um período de quase quinze anos. Os demais locais de compra foram agregados em uma mesma categoria, denominada "outros", como nas análises dos demais produtos.

É possível identificar que o varejo de alimentos no Brasil está concentrado nos três formatos de maior participação - o supermercado, a padaria e a mercearia com participação conjunta de $66,07 \%$ em 1995/1996 e de 62,71\% em 2008/2009. A queda desse período se deve exclusivamente à redução da participação das padarias, caindo de $17,37 \%$ na primeira pesquisa para $13,09 \%$ na última.

O ganho de importância relativa de formatos como mercado, mercearia e hipermercado, pode ser identificado da mesma forma que a perda da importância de ambulante, açougue e feira livre. Outro dado importante é o aumento da participação dos demais locais de compra identificados na categoria "outros", que possuíam uma participação de apenas 5,43\% no início do período e subiram para $14,10 \%$ na última

14 R. Adm. FACES Journal Belo Horizonte v. 17 n. 3 p. 8-27 jul./set. 2018. ISSN 1984-6975 (online). ISSN 1517-8900 (Impressa) http://dx.doi.org/10.21714/1984-6975FACES2018V17N3ART5278 


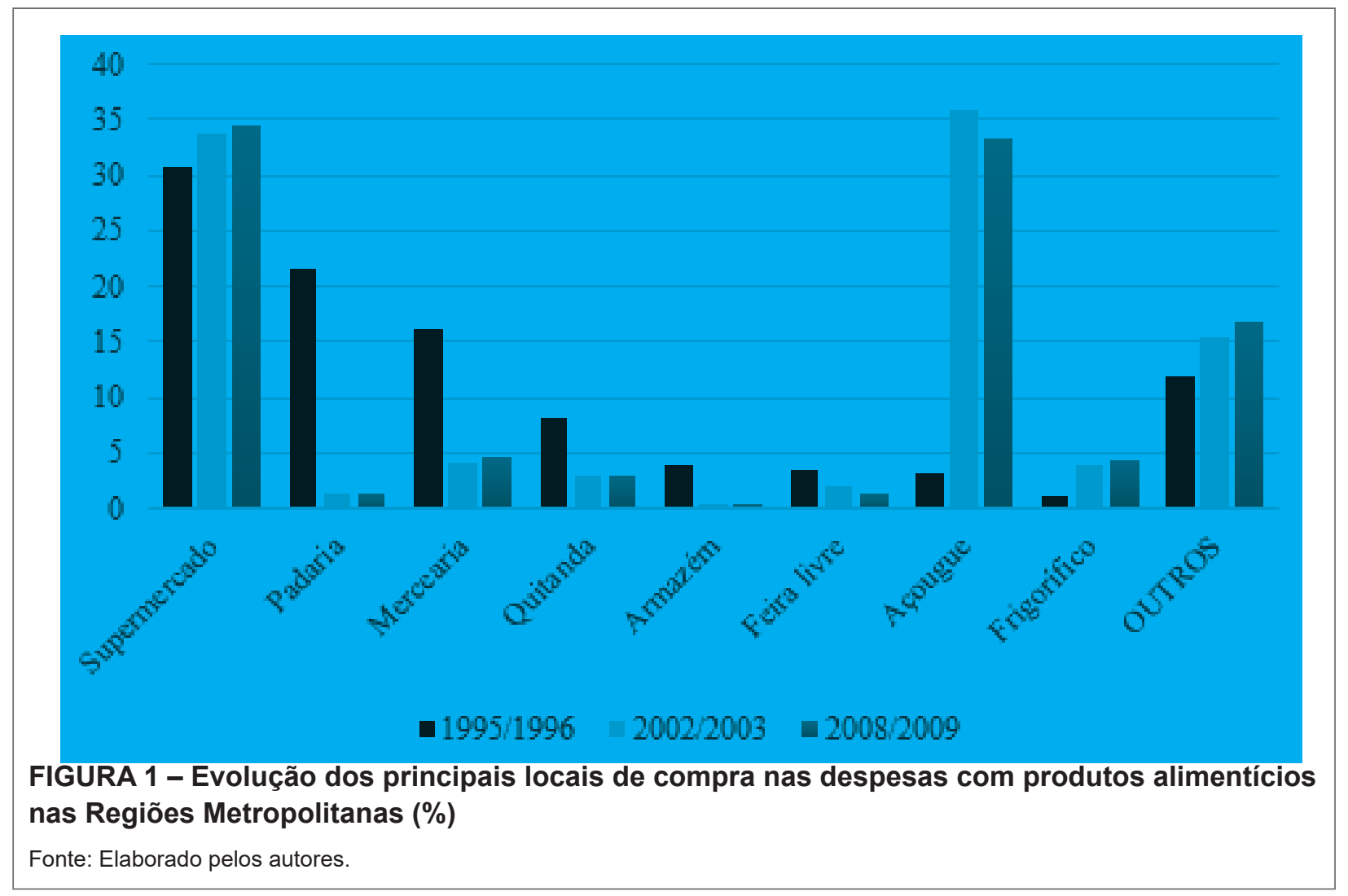

pesquisa. $O$ supermercado foi o formato mais utilizado na aquisição de alimentos, com participação relativamente estável durante o período de aproximadamente 35\% das compras.

De acordo com pesquisas, apenas as empresas de supermercados e hipermercados concentravam $74,60 \%$ do faturamento total do varejo alimentício em 2002. O surgimento dos hipermercados na lista dos dez principais varejos alimentícios a partir da edição da POF de 2002/2003 indica o crescimento da sua importância, embora isso não se traduza em maior participação, restrito a apenas 2, I I\% (FUNDAÇÃO GETÚLIO VARGAS - FGV, 2003).

Apesar de vários formatos tradicionais concentrarem grande participação na compra de diversos produtos, como as compras de pães e laticínios nas padarias, os supermercados se tornaram mais competi- tivos nas últimas décadas em função de pesados investimentos nas seções de carne, hortaliças, frutas e panificados (PARENTE, 2000). Isso pode explicar a queda de participação da padaria, quitanda, feira livre e açougue no comércio de alimentos nas regiões metropolitanas brasileiras.

Uma tendência identificada na última década é o crescimento dos supermercados de bairros, aumentando a concorrência com os formatos tradicionais do comércio local, o que pode explicar a queda da participação das padarias (EUROMONITOR, 20I5). Ocorre um aumento da presença de pequenas lojas das grandes redes varejistas atuando no comércio de vizinhança. $O$ faturamento, em dólar, dessas pequenas lojas subiu $15 \%$ em 2014 , enquanto o faturamento dos hipermercados e dos supermercados tradicionais cresceu apenas 0,5\% e 2,3\%, respectivamente. $O$ instituto de pesquisa 
concluiu que os principais fatores que explicam os aumentos do volume de negócios no comércio de alimentos em bairros são as mudanças de hábitos da população, como maior busca por conveniência, e a tentativa de minimizar os impactos da mobilidade urbana na rotina dos consumidores.

O crescimento do varejo de bairro no Brasil pode ser identificado nas estratégias de diferentes redes varejistas. Por exemplo, a rede Carrefour já está inserida no comércio da vizinhança desde 2010 , com a bandeira Carrefour Bairro. Em 20I4, deu-se início a uma nova investida, agora sob a bandeira Carrefour Express, formato de lojas com $200 \mathrm{~m}^{2}$ e cerca de 2,7 mil itens básicos e de consumo rápido. Outros grupos, como o Pão de Açúcar e a espanhola Dia\%, já se inseriram nesse mercado e planejam crescimento (EUROMONITOR, 20I5).

De acordo com Woxenius (20I2), grandes congestionamentos, vias inseguras e infraestrutura urbana conduzem a uma maior duração dos deslocamentos. $\mathrm{Na}$ tentativa de poupar tempo na compra de certos produtos, em especial produtos de pouco valor agregado, os consumidores se encaminham para o comércio dos bairros (LIMA JÚNIOR, 20II). Segundo informações da POF, esses tipos de varejo representavam juntos $16,21 \%$ das compras de alimentos, em 1995/1996, subindo para 20,01\%, em 2008/2009. Mesmo no período do surgimento de novos varejos, como hipermercados, e da expansão das redes supermercadistas, esses varejos aumentaram sua participação relativa.

O setor de higiene pessoal, cosméticos e perfumaria ganhou dinamismo nas últimas décadas apoiado no crescimento da renda das famílias brasileiras e no maior gasto destinado a esses produtos. A venda direta é o canal mais utilizado na aquisição de produtos de higiene, tendo sua participação crescido de 24,25\% em 1995/l996 para 27,55\% em 2008/2009 (Figura 2). Empresas como Avon e Natura criaram uma importante rede de distribuição baseada no setor de vendas compostas por trabaIhadores autônomos.

O forte crescimento do setor de venda direta entre os anos de 2001 e 2010 (taxa média anual de $14,87 \%$ a.a.) foi sustentado por três fatores: relacionamento, produtos de qualidade e conveniência (TERZIAN, 2010). O último fator está ligado fortemente aos desafios de mobilidade urbana. $A$ aquisição de produtos em grandes cidades mal planejadas, como as brasileiras, exige dos consumidores recursos financeiros e tempo para concretizar a compra, tornando pouco conveniente o processo de compra. A venda direta, por sua vez, atrai consumidores com a promessa de facilidade na retirada dos produtos comprados, não havendo deslocamento ou limitando-o.

Varejos tradicionais especializados em produtos de higiene e cosméticos, como lojas de cosméticos/perfumarias e farmácia/drogarias, cresceram sua participação durante o período analisado, passando de 25,83\% na primeira edição para $31,43 \%$ na última. Considerando os varejistas especializados como um todo, os tradicionais e venda direta, a participação cresceu de $50,18 \%$ para $58,98 \%$. Apenas as farmácias e drogarias passaram de II,92\% para I5, I I\%. Ao mesmo tempo, os supermercados caíram de $12,25 \%$ para $9,31 \%$.

A mais fácil instalação de farmácias e drogarias em localizações privilegiadas, em função do menor espaço necessário para a loja, e o horário diferenciado de atendimento, permanecendo abertas por um pe- 


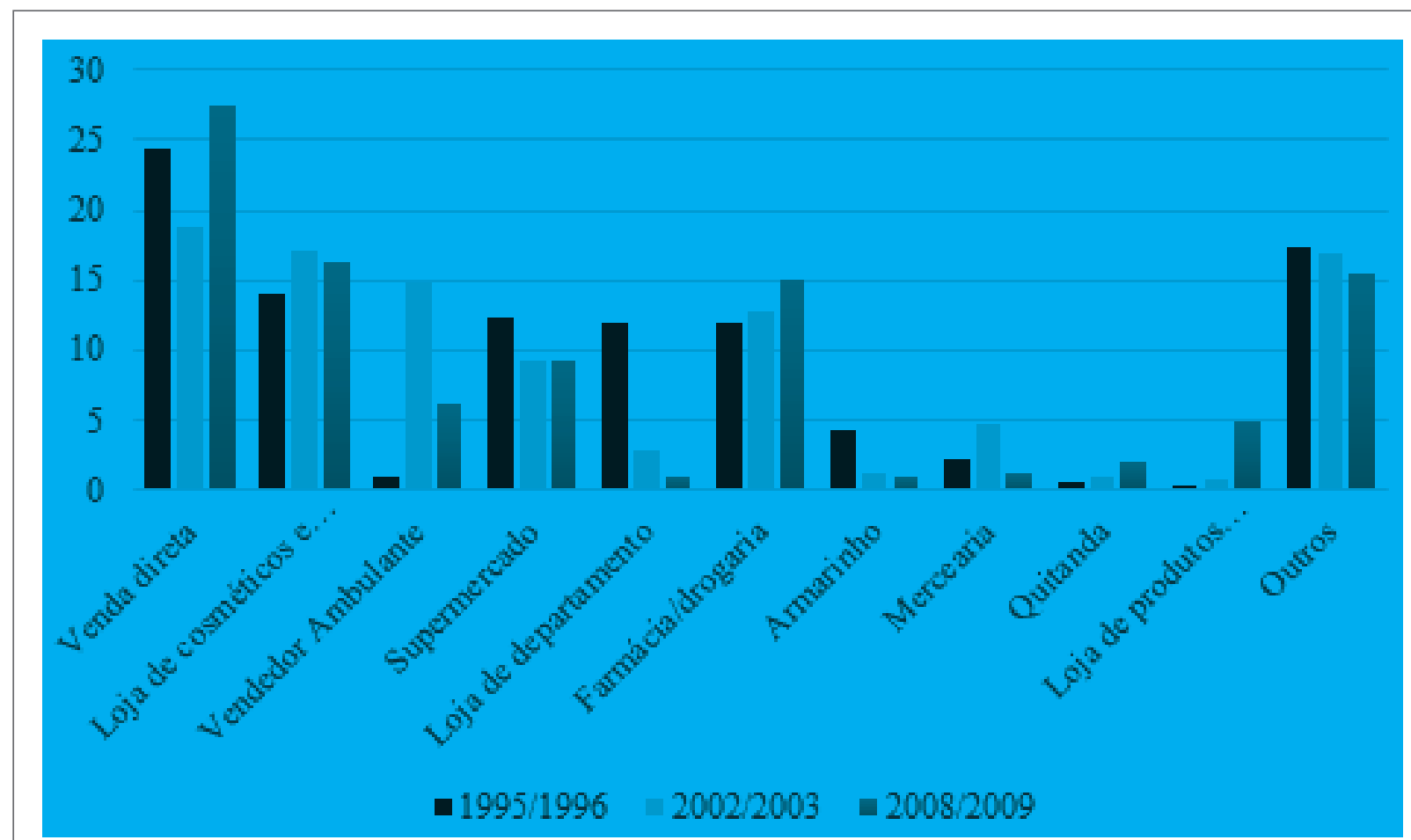

FIGURA 2 - Evolução dos principais locais de compra nas despesas com produtos de higiene (\%)

Fonte: Elaborado pelos autores.

ríodo maior, influenciam a escolha do varejista pelos consumidores. $O$ deslocamento desses comércios para os bairros pode explicar a maior preferência do consumidor por comprar esses bens nas farmácias e drogarias, bem como a melhoria nas sessões de produtos não farmacêuticos (EUROMONITOR, 20I5).

No varejo de artigos de vestuário, as lojas de roupas foram o formato de varejo mais escolhido pelas famílias brasileiras para a compra de produtos de vestuário. $A$ participação elevada no início do período, de $61,54 \%$, subiu um pouco mais no final do período, passando para 65,81\% (Figura 3).A queda da participação das lojas de departamento, de $15,04 \%$ para $7,01 \%$, pode ser explicada pela concorrência dos pequenos comércios de bairro, que possuem melhor localização e marcas mais valorizadas. As lojas de departamento necessitam se instalar em médios e grandes estabele- cimentos, o que dificulta sua manutenção nas regiões centrais. Consequentemente, precisam de grande volume de vendas para se manterem vigentes no mercado, o que inibe que se instalem em bairros.

A escolha dos consumidores por roupas está muito pautada em fatores como marca e qualidade, como indica a pesquisa Consumer Lifestyles in Brazil, realizada pelo Euromonitor (20I4). Logo, tipos de varejo especializados na venda desses bens têm maior possibilidade de atender esses atributos. Portanto, pode considerar que conveniência não é o fator mais relevante na determinação da escolha da loja, em especial das compras planejadas.

De acordo com as informações da POF, as lojas de eletrodoméstico eram responsáveis por mais da metade das vendas de equipamentos elétricos no início do período caindo para $43,66 \%$, embora o formato ainda se mantenha como o principal varejo 


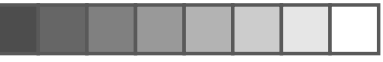

ALTERAÇÕES NOS HÁBITOS DE COMPRA E DISTRIBUIÇÃO VAREJISTA
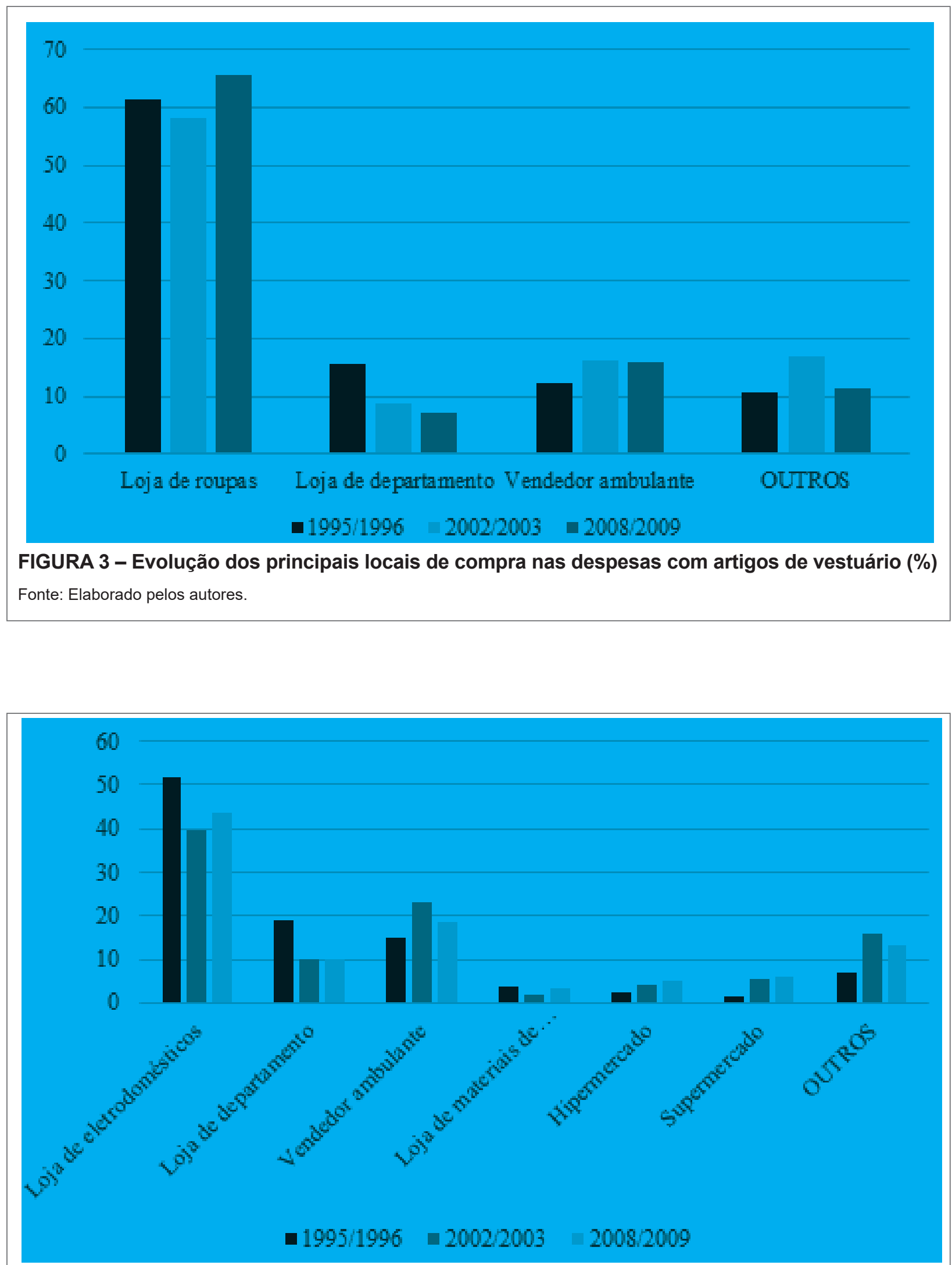

FIGURA 4 - Evolução dos principais locais de compra nas despesas com Produtos Eletrônicos (\%)

Fonte: Elaborado pelos autores.

18 R. Adm. FACES Journal Belo Horizonte v. 17 n. 3 p. 8-27 jul./set. 2018. ISSN 1984-6975 (online). ISSN 1517-8900 (Impressa)

http://dx.doi.org/10.21714/1984-6975FACES2018V17N3ART5278 
deste setor. Uma queda parecida ocorreu com a procura por lojas de departamento, de $18,86 \%$ para 10,17\% (Figura 4).

No mesmo período, as compras em super e hipermercados aumentaram, passando de 4,95\% para II,27\%, tornando-se, juntos, a terceira opção mais procurada na compra desses bens. $O$ aumento da busca por redes supermercadistas para a aquisição deste tipo de bens se deve, em primeiro lugar, aos investimentos feitos nessas seções (PARENTE, 2000). O aumento da variedade desses itens nas gôndolas, aliado a praticidade de realizar essa aquisição junto com as compras do mês, tornam as redes supermercadistas mais atrativas.

Na última edição, 2008/2009, foi possível identificar o aumento da importância atribuída à loja de informática e ao comércio (loja) virtual. $\mathrm{O}$ primeiro, apoiado nos atributos de loja especializada, ou seja, maior variedade de produtos e atendimento diferenciado; o segundo, na conveniência e no preço.

\section{Comparação entre o varejo das regiões metropolitanas e das cidades do interior}

Lima Júnior (20 I I), afirma que a falta de planejamento das cidades brasileiras é a causa essencial dos problemas de mobilidade e logística urbanas. $O$ crescimento urbano das cidades mal planejadas resulta em maior deterioração da mobilidade urbana (GATTI JÚNIOR, 20II). Problemas de mobilidade urbana interferem na qualidade de vida da população e em seus hábitos de consumo, resultando na busca dos consumidores por alternativas mais viáveis para manutenção do próprio consumo (LIMA JÚNIOR, 20II).

Para entender como as questões de mobilidade urbana afetam o varejo, basta comparar as escolhas dos locais de com- pra pelos consumidores residentes nas regiões metropolitanas e nas cidades do interior nas edições 2002/2003 e 2008/2009 da POF. Essas diferenças podem esclarecer como a mobilidade urbana afeta as forças do varejo nas grandes cidades. A análise se concentrará em Produtos Alimentícios, Artigos de Higiene, Artigos de Vestuário e Artigos Eletrônicos.

Os resultados agregados para o comércio de alimentos apresentaram pequenas diferenças quanto à preferência de locais de compra. Com relação à lista de principais varejistas procurados para a obtenção de alimentos, o hipermercado é o nono varejo mais procurado pelas famílias residentes nas regiões metropolitanas. No entanto, não consta na lista dos principais varejos buscados pelos moradores do interior. $O$ formato hipermercado exige escala para se tornar viável, ou seja, o volume de vendas deve ser maior, o que impede uma participação mais ativa em cidades menores. Da mesma forma, o vendedor ambulante, que aparece em oitavo lugar na preferência dos consumidores do interior, não tem o mesmo destaque para moradores metropolitanos, fato que pode ser explicado pelo maior dinamismo do varejo das grandes cidades.

Com relação ao principal varejo utilizado na compra de alimentos, o supermercado participa com 35,95\% nas regiões metropolitanas e $38,12 \%$ nas cidades do interior. O comércio tipicamente de bairro, como açougue, padarias, mercearias, mercado, armazém, quitanda e sacolão, representa $45,38 \%$ das escolhas dos consumidores nas regiões metropolitanas, enquanto no interior detêm a participação de 37,84\%, na edição de 2008/2009 (Figura 5). Essa diferença pode ser associada ao maior dinamismo do comércio dos bairros, resultante 
da mudança de hábitos dos consumidores visando minimizar os problemas envolvendo a mobilidade dos grandes centros urbanos (EUROMONITOR, 20I4).

A comparação dos subgrupos de alimentos revela diferenças mais significativas no comércio de frutas e carnes. Os principais locais de compra escolhidos para a compra de frutas variam com a região analisada.Tanto nas regiões metropolitanas quanto nas cidades do interior, o principal formato varejista na venda de frutas é o supermercado. No entanto, a participação nas regiões metropolitanas é mais importante que no interior, com participação de $31,02 \%$ e $26,29 \%$, respectivamente, na edição de 2008/2009.

Nas cidades do interior, a feira livre rivaliza com o supermercado como o principal local de compra de frutas, com participação de $23,72 \%$, enquanto nas regiões metropolitanas esse formato é apenas o terceiro mais utilizado, representando apenas II,92\% das compras.A feira livre é o tipo de varejo que se caracteriza por não possuir loja física, ocorrendo normalmente em vias públicas e dias específicos (MAINVILLE, 2002).

Embora apenas na cidade de São Paulo ocorram aproximadamente 900 feiras semanais, este varejo vem perdendo espaço para as lojas físicas no gosto dos consumidores das grandes cidades, em especial para o supermercado e para outros formatos hortifrúti. Apesar de ofertar grande variedade de produtos frescos, atendimento pessoal e ser um formato tradicional, as feiras, em geral, só funcionam uma vez na semana e em período limitado de tempo, afetando o atributo de conveniência (BELIK, 2000; MAINVILLE, 2002).

$O$ varejo de artigos de higiene pessoal, cosméticos e perfumaria possui algumas distinções entre as duas regiões. Embora a

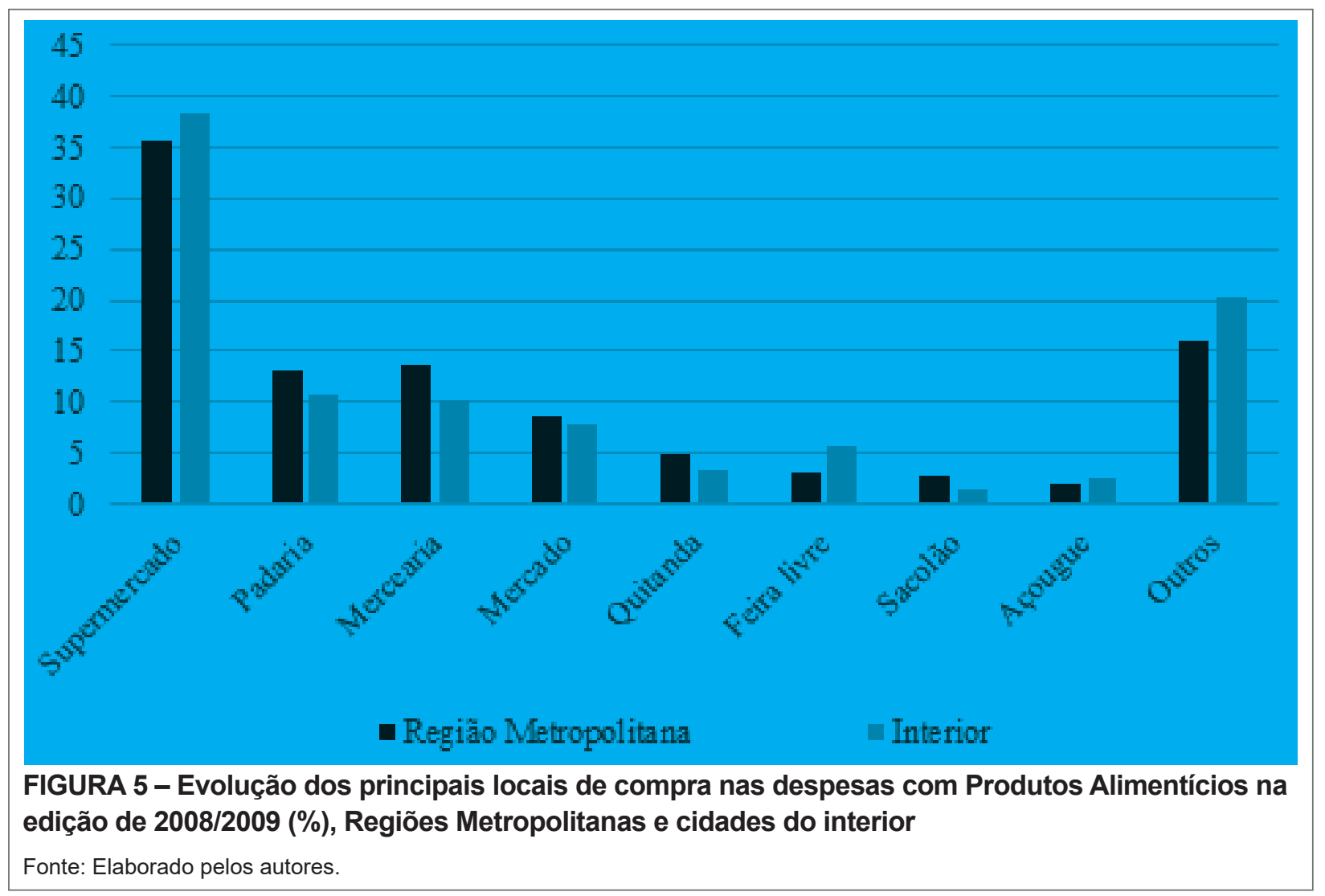

20 R. Adm. FACES Journal Belo Horizonte v. 17 n. 3 p. 8-27 jul./set. 2018. ISSN 1984-6975 (online). ISSN 1517-8900 (Impressa) http://dx.doi.org/10.21714/1984-6975FACES2018V17N3ART5278 
venda direta tenha sido o canal mais utilizado na aquisição desses bens nas regiões metropolitanas desde a edição de 2002/2003, este formato só se consolidou como a principal escolha do consumidor do interior na edição seguinte (2008/2009). Embora possua maior importância para os consumidores das regiões metropolitanas, 27,55\%, do que para os consumidores do interior, $23,58 \%$. Como dito anteriormente, a venda direta oferece conveniência ao consumidor, evitando, ou restringindo, deslocamentos na aquisição dos produtos (Figura 6).

As farmácias e drogarias foram as principais opções na compra de artigos de higiene no interior em 2002/2003, com participação de $21,84 \%$, passando a ocupar o quarto lugar na preferência do consumidor na edição de 2008/2009, com participação de II,22\%, atrás da venda direta, do supermercado e das lojas de cosméticos e perfumaria. Nas regiões metropolitanas, esses formatos cresceram no período, passando de $12,84 \%$ para $13,28 \%$, se tornando o terceiro varejo mais preferido pelo consumidor para a aquisição desses bens.

Nas cidades do interior, o supermercado tem papel de destaque nesse mercado. $\mathrm{Na}$ edição 2002/2003, este formato foi responsável por 15,52\% das vendas de produtos de higiene pessoal, enquanto nas regiões metropolitanas sua participação não excedia $9,3 \%$. Na edição seguinte, o supermercado ganhou ainda mais espaço nas escolhas dos clientes do interior, 17,44\%, enquanto nas zonas metropolitanas manteve a mesma participação.

Lojas especializadas em cosméticos e perfumaria são o segundo destino de compras deste setor nas regiões metropolitanas nas duas edições, com participação média de $17 \%$. Enquanto nas cidades do interior, este formato apenas ganhou importância na última edição, crescendo de $4,34 \%$ para $15,21 \%$.

No setor de artigos de vestuário, como observado na análise da série histórica das regiões metropolitanas, as lojas de roupas foram o formato varejista mais utilizado pelas famílias residentes nas cidades do interior. Com elevada participação, a preferência por este formato cresceu de $56,55 \%$ na edição de 2002/2003 para 68,29\% em 2008/2009 (Figura 7).

Os vendedores ambulantes assumiram a segunda colocação em ambas as regiões e as lojas de departamento mostraram-se mais importantes nas regiões metropolitanas que nas cidades do interior, 7,01\% contra $3,28 \%$. Esse fato pode estar associado ao maior volume de vendas necessário para manter vigentes esses empreendimentos, restringindo a instalação desses formatos em cidades menores.

De acordo com o Euromonitor (20l4), a escolha dos consumidores por roupas está muito pautada nos atributos de marca e qualidade. Logo, a localização e a conveniência ficam em segundo plano na decisão de compra desses bens. A elevada opção por lojas de roupas pode ser atribuída, então, à melhor capacidade deste formato em atender tais atributos, e não a busca por conveniência.

De acordo com as informações da POF para as despesas com artigos eletrônicos, parte significativa dos eletrodomésticos, eletroeletrônicos e aparelhos elétricos é comercializados nas lojas de eletrodomésticos, responsáveis pela venda de $43,66 \%$ das aquisições desses bens nas regiões metropolitanas e 46,19\% nas cidades do interior. Durante o período analisado, 2002 a 2009, em ambas as regiões as vendas desses bens se concentraram no principal varejo (Figura 8). 

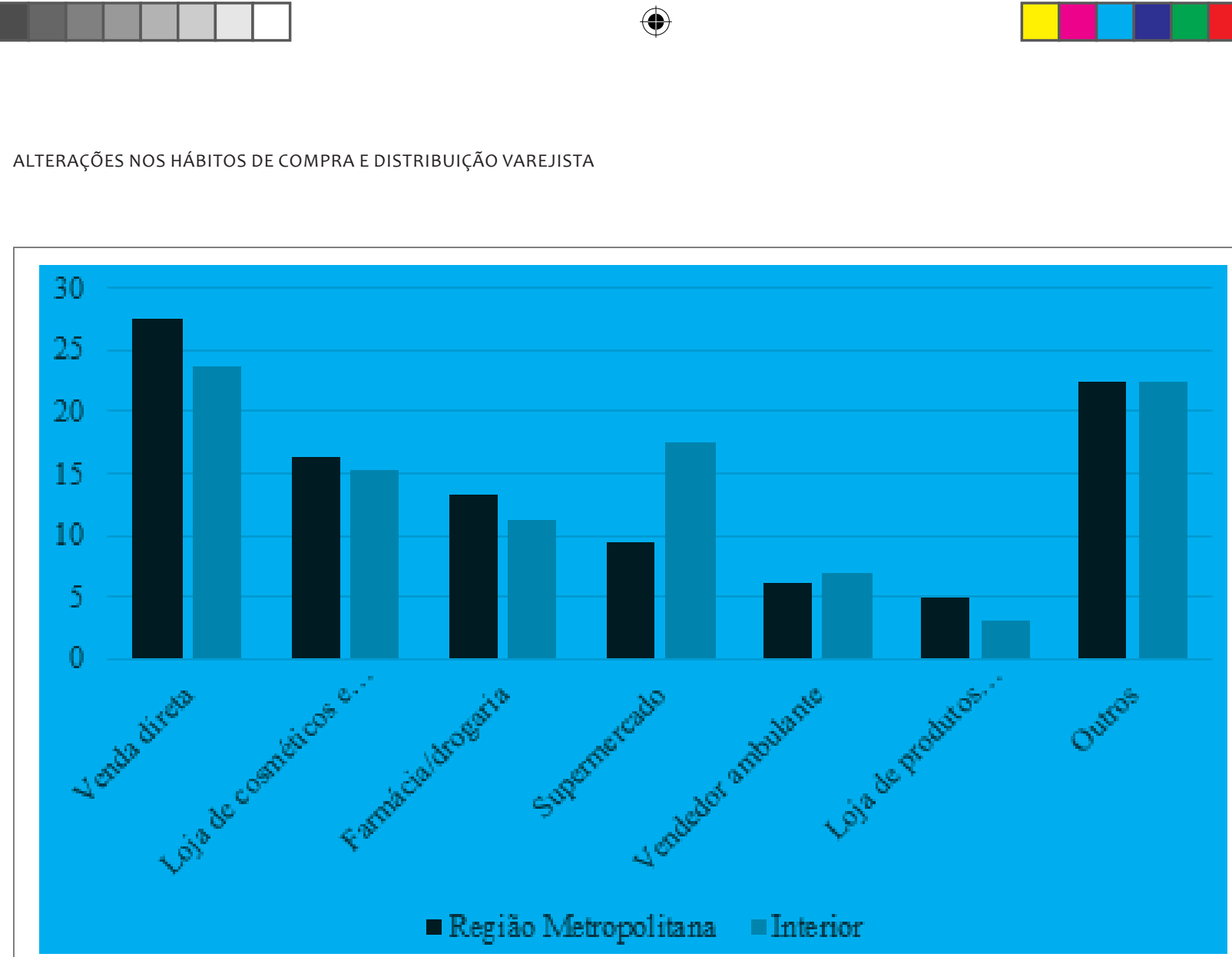

FIGURA 6 - Evolução dos principais locais de compra nas despesas com Artigos de Higiene Pessoal na edição de 2008/2009 (\%), Regiões Metropolitanas e cidades do interior

Fonte: Elaborado pelos autores.

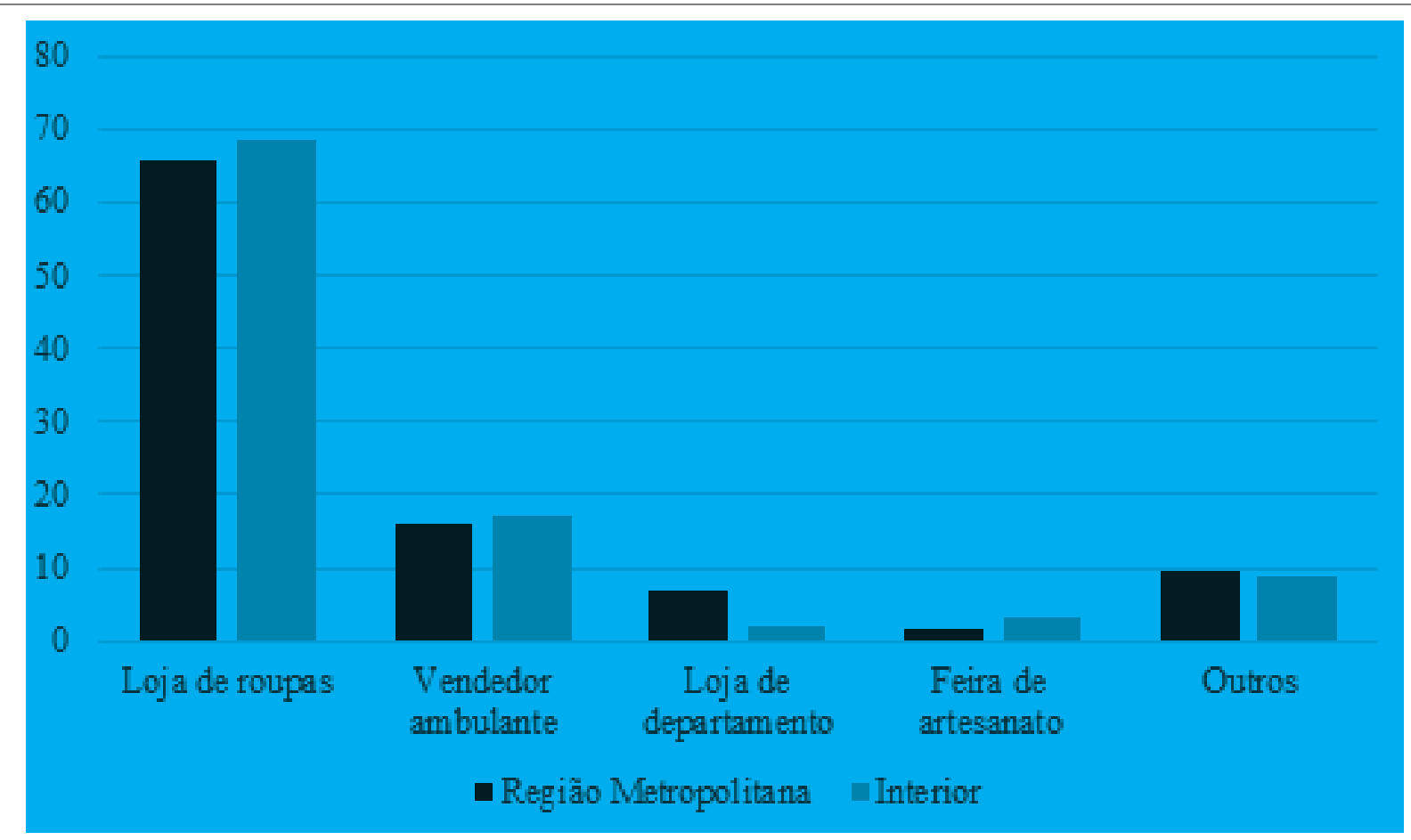

FIGURA 7 - Evolução dos principais locais de compra nas despesas com Artigos de Vestuário na edição de 2008/2009 (\%), Regiões Metropolitanas e cidades do interior

Fonte: Elaborado pelos autores.

22 R. Adm. FACES Journal Belo Horizonte v. 17 n. 3 p. 8-27 jul./set. 2018. ISSN 1984-6975 (online). ISSN 1517-8900 (Impressa)

http://dx.doi.org/10.21714/1984-6975FACES2018V17N3ART5278 
As compras em lojas especializadas, como de eletrodomésticos, de informática e de materiais elétricos, representam $44,85 \%$ das vendas nas regiões metropolitanas e 47,68\% no interior. Enquanto varejos massificados, como lojas de departamento, supermercados e hipermercados, representaram uma parcela menor, 21,44\% nas metrópoles e $12,55 \%$ nas cidades do interior.

Os artigos eletrônicos podem ser considerados bens de comparação, caracterizados pela compra pouco frequente e pelo valor mais alto.A compra desse bem envolve uma pesquisa prévia por parte do consumidor. Isso torna a compra por impulso bem menor. Devido à baixa frequência de vendas, não é econômico disponibilizar esses produtos em qualquer loja, restringindo os locais de compra (NOVAES, 2007).

A baixa presença do pequeno varejo nesse mercado é consequência direta da distribuição utilizada. Segundo Novaes (2007), a ampla distribuição de alguns produtos não é eficiente em função dos altos custos que envolvem a comercialização e a própria distribuição. Dessa forma, pequenos comércios ficam em posição de desvantagem neste mercado, visto que incorrem em custos maiores. Portanto, o mercado fica concentrado nas mãos de médias e grandes empresas.

O fato de a compra de artigos eletrônicos exigir um montante financeiro maior e, em geral, uma pesquisa prévia do consumidor, torna a compra como um todo previsível. Para Kahn e Schmittlein (1989), os consumidores estão dispostos a se deslocar mais por compras regulares, previsíveis e, ou, mais caras. Logo, os resultados indicam que as questões de mobilidade urbana parecem não afetar de forma decisiva esse setor do varejo.

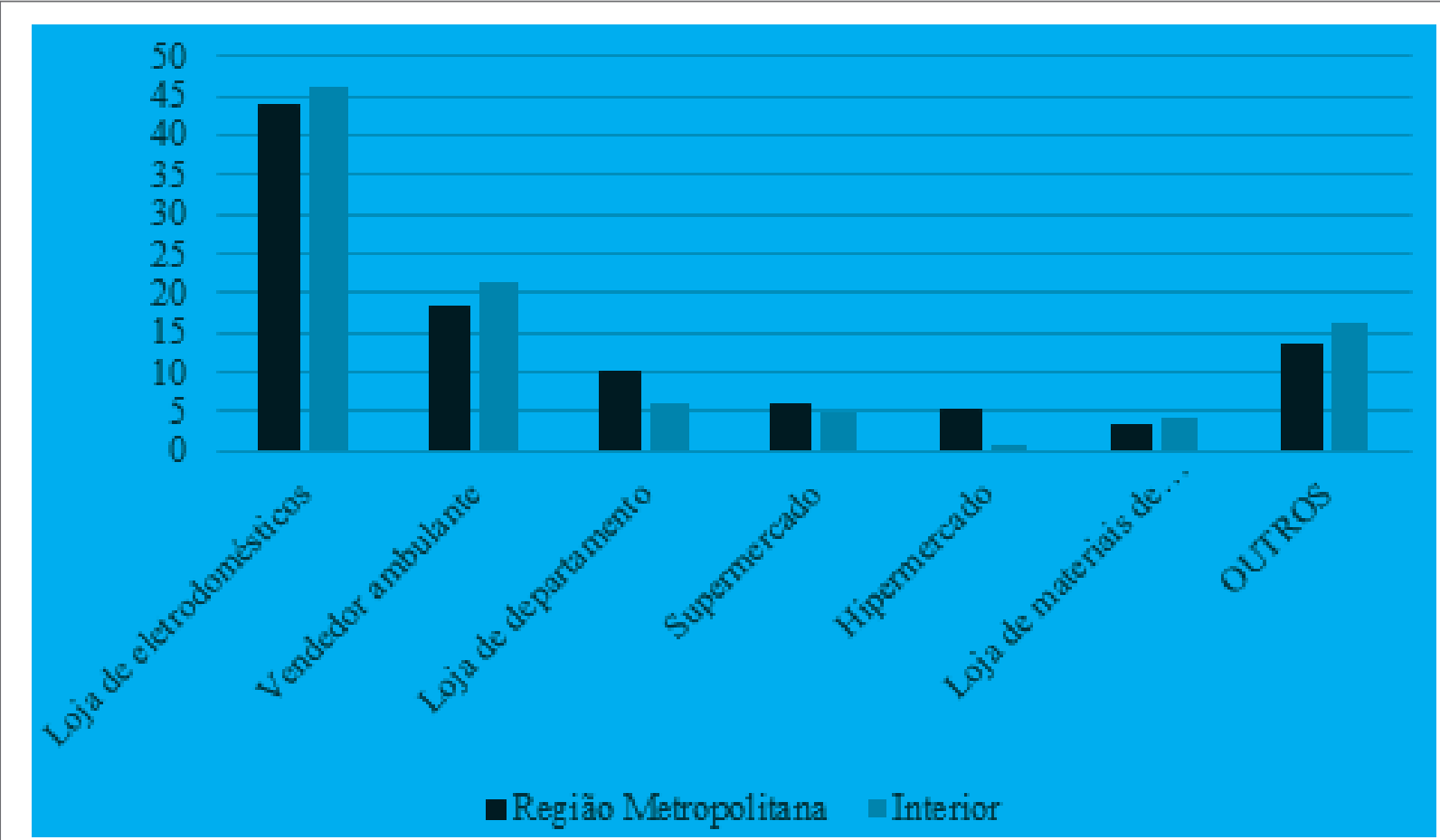

FIGURA 8 - Evolução dos principais locais de compra nas despesas com Artigos de Vestuário na edição de 2008/2009 (\%), Regiões Metropolitanas e cidades do interior

Fonte: Elaborado pelos autores. 


\section{INFLUÊNCIAS DAS ALTERAÇÕES NAS FORÇAS DO VAREJO NA LOGÍSTICA}

De acordo com Zinn (20I2), a busca por eficiência na distribuição e redução dos custos com estoques, além da melhoria no cumprimento de prazos e na qualidade do serviço, são as principais contribuições da logística ao negócio. Apesar desses esforços, os desafios de mobilidade urbana, resultante do pouco ou inexistente planejamento das grandes cidades brasileiras, conduz à maior complexidade e custo da distribuição urbana de cargas (LIMA, 2003).

A migração do varejo para o comércio de bairro resulta em alguns impactos para as empresas. Em primeiro lugar, ocorre uma dispersão dos pontos de venda ao longo da área urbana, resultando em maior deslocamento da frota de cargas. Além da dispersão, ocorre ao mesmo tempo um aumento do número de pontos de venda, visto que o comércio dos bairros se torna mais dinâmico, abrigando maior número de estabelecimentos em um comércio mais especializado. Por último, os centros comerciais dos bairros são compostos por empreendimentos menores, que visam atender uma área geograficamente menos dispersa. Portanto, as empresas precisam atender lotes menores, incorrendo em maiores custos.

Um outro resultado encontrado na análise dos dados da POF foi o aumento da participação dos formatos de varejo menos importantes, agregados na categoria "outros", em quase todos os grupos de despesas, em especial, com alimentos. Esse aumento na importância de varejos não tradicionais indica que o setor de alimentos adotou a estratégia de multiplicidade de pontos de venda. De acordo com Zinn (20|2), essa estratégia afeta a distribuição logística das empresas, visto que o aumento do número de pontos de venda, juntamente com a redução dos lotes, torna o serviço mais complexo e caro.

Para atender esse novo cenário, com pedidos com lotes menores e dispersos pela cidade, as empresas precisam criar uma nova estrutura de distribuição. Para isso são necessárias a construção de novos centros de distribuição e a criação de uma frota com veículos menores prontos a atender a reposição de estoques das pequenas lojas de forma ágil, evitando a ocorrência de rupturas. $O$ resultado é um aumento dos estoques dos fabricantes e atacadistas, além de um número maior de veículos de cargas nas ruas.

Apesar dos transtornos causados a população, o poder público não consegue solucionar os problemas provocados pela distribuição de cargas. Medidas restritivas na circulação da frota de cargas resultam no oposto do esperado. Apenas aumentam o tempo de viagem, fazendo com que o veículo permaneça um período maior no trânsito, e o número de veículos inicial, já que os mesmos não conseguem atender o volume inicial graças à queda na eficiência do serviço (OGDEN, 1992). O resultado é o aumento do tráfego de automóveis, da poluição e dos congestionamentos (QUISPEL, 2002).

\section{CONSIDERAÇÕES FINAIS}

A pesquisa desenvolvida neste estudo foi conduzida com o objetivo de encontrar evidência sobre o retorno dos consumidores ao varejo dos bairros a partir do comportamento de compra por conveniência, bem como discutir os impactos desta redistribuição espacial para a logística de distribuição nas grandes cidades.

A valorização da conveniência nas decisões

24 R. Adm. FACES Journal Belo Horizonte v. 17 n. 3 p. 8-27 jul./set. 2018. ISSN 1984-6975 (online). ISSN 1517-8900 (Impressa) http://dx.doi.org/10.21714/1984-6975FACES2018V17N3ART5278 
de compra e as restrições de deslocamento em função dos congestionamentos tornaram os estabelecimentos mais próximos dos domínios mais atraentes ao consumidor na aquisição de certos bens. A escolha dos estabelecimentos está relacionada ao produto que se quer adquirir, à frequência de visitas ao estabelecimento e ao tempo de deslocamento para se realizar a compra.

$A$ análise sugere que a escolha dos locais de compra dos produtos alimentícios e dos produtos de higiene pessoal foi alterada ao longo do período, migrando para formatos que oferecem maior conveniência e menor tempo para efetivar as compras. A migração desses setores varejistas para formatos tipicamente de bairro indica que o varejo localizado nas vizinhanças cresce apoiado nesses fatores. Isso também é reforçado pela comparação no varejo de alimentos entre as despesas realizadas pelas famílias residentes nas regiões metropolitanas e aquelas realizadas nas cidades do interior, quando ficou evidenciado que o comércio tipicamente de bairro concentra uma parcela maior das despesas de alimentos nas regiões metropolitanas do que das cidades do interior.

No primeiro caso, do varejo de produtos alimentícios, o aumento da propensão dos consumidores a adquirem estes produtos na proximidade de suas residências estimulou o crescimento do número de estabelecimentos classificados como supermercados, de médio porte, bem como do número de estabelecimentos e da diversificação de itens nas padarias, nos sacolões e açougues. Também estimulou o crescimento do número de restaurantes para o atendimento a um público local crescente do comércio e das famílias. Ao se comparar as despesas dos subgrupos de alimentos selecionados, foi possível identificar diferenças mais significativas no comércio de frutas e carnes, indicando que a mobilidade urbana interfere nesse comércio.

As vendas dos estabelecimentos que oferecem artigos de higiene pessoal, cosméticos e perfumaria estão concentradas em três formatos: venda direta, lojas de cosméticos e perfumaria e farmácias e drogarias. $A$ participação das compras desses bens por venda direta aumentou ao longo do período analisado, indicando que a conveniência de comprar o produto sem se deslocar tornou-se mais importante para o consumidor. As farmácias e drogarias também aumentaram sua participação no mercado, oferecendo a comodidade de localização e horário diferenciado de atendimento.

De qualquer forma, o formato de comércio forte nos bairros é um fenômeno que se auto reforça. Quanto mais se compra nos bairros, mais entregas são necessárias, portanto, mais veículos de carga circulando, menos mobilidade das pessoas, e, por conseguinte, menor propensão a deslocarem-se. Concomitantemente a isso, elevam-se os custos da distribuição e aumenta-se a complexidade da gestão do varejo, com dificuldades principalmente de precisão nos lotes de compras e maiores riscos de ruptura.

Mas, é certo que a mobilidade age diretamente sobre os preços dos produtos, aumentando os custos logísticos unitários da distribuição. A migração do comércio para os bairros resulta na necessidade da criação de uma nova estrutura de distribuição, com novos centros de distribuição e frota com veículos menores. O resultado é um aumento dos estoques dos fabricantes e atacadistas, além de um número maior de veículos de cargas nas ruas, aumentando os custos das empresas. 


\section{REFERÊNCIAS}

ARSHINDER, K.; KANDA, A.; DESHMUKH, S. G. A Review on Supply Chain Coordination: Coordination Mechanisms, Managing Uncertainty and Research Directions. In: CHOI, T.-M.; CHENG, T. C. E. (Eds.). Supply Chain Coordination under Uncertainty, Berlin, Heidelberg: Springer-Verlag Berlin Heidelberg, p. 39-82, 201 I.

BALLANTYNE, E.; LINDHOLM, M.; WHITEING, A. A comparative study of urban freight transport planning: addressing stakeholder needs. Journal of transport geography, v. 32, p. 93-10I, 2013.

BELIK,W. Mecanismos de Coordenação na Distribuição de Alimentos no Brasil. In: BELIK, W. \& MALUF, R.S. (edit.). Abastecimento e Segurança Alimentar. Campinas, SP: IE/UNICAMP, 2000.

BURT, S.; MAVROMMATIS, A. The international transfer of store brand image. Int. Rev. of Retail, Distribution and Consumer Research, v. I6, n. 4, p. 395-4I3, 2006.

CARVALHO,J.L. G. O comportamento de compra e a percepção do consumidor em relação às marcas das redes de supermercados em Londrina. Dissertação (Mestrado em Administração - Gestão de Organizações). Universidade Estadual de Londrina - UEL / Universidade Estadual de Maringá UEM, Londrina, 2004.

EUROMONITOR. The Power of Proximity: The Complex Story of 2 Ist Century Cities, 201I. Acessado em <www.euromonitor.com> em jan. de 2015 .

EUROMONITOR. Consumer lifestyles in Brazil, 2014. Acessado em <www.euromonitor.com> em jan. de 2015.

EUROMONITOR. Global Consumer Trends for 2015, 2015.
Acessado em <www.euromonitor.com> em jan. de 2015.

FUNDAÇÃO GETÚLIO VARGAS

- FGV. Impactos Verticais da Concentração do Setor Varejista Brasileiro. São Paulo, 2003.

FUJITA, M. A monopolistic competition model of spatial agglomeration: Differentiated product approach, Regional Science and Urban Economics 18, 87124, 1988.

GATTI JUNIOR, W. A ZMRC e o transporte urbano de cargas na cidade de São Paulo, 20I I.

GIL, A. C. Métodos e técnicas de pesquisa social. In: Métodos e técnicas de pesquisa social. 2015.

GRANDINI, A. Ciclo de Palestras AMCHAM: tendências da logística e do supply chain

management. Campinas, 2009.

INSTITUTO BRASILEIRO DE GEOGRAFIA E ESTATÍSTICA - IBGE. IBGE Cidades. Disponível em: <http://www.ibge.gov.br/cidadesat/topwindow.htm?l> Acesso em 06 de fevereiro/2018.

KAHN, B.; SCHMITTLEIN, D. Shopping trip behavior: an empirical investigation. Marketing Letters, 1989.

KOTLER, P.; KELLER, K. Administração de marketing. 12. ed. São Paulo: Pearson Prentice Hall, 2006.

LIMA, R. Bases para uma metodologia de apoio à decisão para serviços de educação e saúde sob a ótica dos transportes. São Carlos: Escola de Engenharia de São Carlos, Universidade de São Paulo, 2003.

LIMA JÚNIOR, O. TENDÊNCIAS PARA A LOGÍSTICA NO SÉCULO XXI. Disponível em: <www. fec.unicamp.br/lalt> Acesso em 06/06/2014

LINDHOLM, M.; BEHRENDS, S. Challenges in urban freight transport planning-a review in the Baltic Sea Region. Journal of Transport Geography, v. 22, p. 129-136, 2012. MAINVILLE, D. Y. The Structure of Fresh Produce Markets in São Paulo: recent developments, trends and implications for market structure. In: CONGRESSO BRASILEIRO DE ECONOMIA E SOCIOLOGIA RURAL, Passo Fundo: SOBER,Anais. Passo Fundo, 2002. ICD-ROM.

MALHOTRA, N. Marketing Research:An Applied Orientation. New Jersey: Prentice Hall, 200 I.

MATTAR, F. N. Pesquisa de Marketing. Edição compacta. São Paulo: Atlas, 200I.

MENTZER, J. T.; STANK, T. P.; ESPER, T. L. Supply chain management and its relationship to logistics, marketing, production, and operations management. Journal of Business Logistics, v.29, n.l, p. 3।-46, 2008.

NOVAES, A. G. Logística e Gerenciamento da Cadeia de Distribuição: Estratégia, Operação e Avaliação. Rio de Janeiro. Editora Campus, 2007.

OGDEN, K. Urban goods movement: a guide to policy and planning. Ashgate. Great Britain, 1992.

OLIVEIRA, L. Uma revisão sistemática da literatura científica em logística urbana no Brasil. Anais do XVII ANPET. Belém, PA, 20I3.

PARENTE, J. Varejo no Brasil. São Paulo:Atlas, 2000.

PINTAUDI, S. M. Os Supermercados na Grande São Paulo - Contribuição ao estudo da transformação do comércio varejista de gêneros alimentícios nas grandes metrópoles. 108 f. Dissertação (mestrado em Geografia) - Departamento de Geografia da Faculdade de Filosofia, Letras e Ciências Humanas, USP / São Paulo, 1981. 
QUISPEL, M. Active partnerships; the key to sustainable urban freight transport. ECOMM 2002 (European Conference on Mobility Management) $15-17$ May, 2002.

ROGERS, H.; GHAURI, P.; GEORGE, $\mathrm{K}$. The impact of market orienta- tion on the internationalization of retailing firms: Tesco in Eastern Europe. The International Review of Retail, Distribution and Consumer Research, v. I5, n. I, p. 53-74, 2005.

SILVA, J. P. G.; CLEPS, G. D. G. O desenvolvimento das redes de asso- ciativismo no setor de autosserviço de Uberlândia - MG, 20I I.

TERZIAN, F.Venda direta não ocorre mais porta a porta. Brasil Econômico, São Paulo, I4 set. 2010.

ZINN, W. Globalização e complexidade em supply chains. Revista Tecnologística, São Paulo, 2012. 